\title{
Evaluasi Nilai Fungsional dan Estetika Taman Maccini Sombala Kota Makassar sebagai Taman Hortikultura
}

\author{
CRI WAHYUNI BRAHMI YANTI 1*, NURFAIDA ${ }^{1}$, \\ A KAISAR ALRIAN PRAMASARANDY1
}

1. Program Studi Agroteknologi, Fakultas Pertanian, Universitas Hasanuddin, Kampus UNHAS Tamalanrea, Jl. Perintis Kemerdekaan Km 10 Makassar 90245, Indonesia

*E-mail : cri_wahyuni@yahoo.com

\section{ABSTRACT \\ Evaluation of Functional and Aesthetic Value of Park Maccini Sombala of Makassar City as Horticultural Parks}

This study aims to evaluate the functional and aesthetic value of Park Maccini Sombala, Makassar as a horticultural park and make recommendations based on the evaluation. The research phases consisted of an inventory phase, analysis, and synthesis. The inventory phase was conducted to collect data on the physical, biophysical and social. The analysis phase was conducted based on descriptive and qualitative analysis on the data collected and KPI (Key Performance Index) assessment for the physical components, the quality of the park, soft materials, hard materials, as well as visitors. Synthesis phase was carried out to make a recommendation of allocation of the park as park horticulture. Evaluation of the functional and aesthetic value indexes of Park Maccini Sombala as horticultural garden result in KPI total value of all components of 0.70 on a scale of $0-1$. The proposed recommendations are divided into general recommendations and the specific recommendations. Addition and improvement of soft and hard material condition are given as the general recommendation, whereas specific recommendations is specified for the allocation of the park as horticultural parks, namely the development of the park's horticultural experimental garden, seed, garden education and research, as well as horticultural tourist park.

Keywords : key performance index, functional and aesthetic evaluation, hortikultura park

\section{Pendahuluan}

Taman kota merupakan ruang terbuka hijau (RTH) kota yang secara optimal digunakan sebagai areal penghijauan dan berfungsi baik secara langsung maupun tidak langsung untuk kehidupan dan kesejahteraan warga kotanya. Keberadaan taman kota sangat penting bagi lingkungan serta masyarakat kota dan merupakan bagian yang tidak terpisahkan dari lanskap perkotaan. Secara umum, taman kota dapat berfungsi secara ekologis, estetika, dan sosial. Akan tetapi, pembangunan taman kota yang terjadi selama 
ini hanya mengutamakan taman kota sebagai penghias kota saja. Padahal taman kota dapat dikembangkan untuk fungsi yang lebih luas dengan taman-taman yang bertema seperti taman hortikultura. Taman hortikultura merupakan suatu area pengembangan hortikultura yang didesain secara multifungsi untuk melestarikan lingkungan, menciptakan, melanjutkan, dan mempercepat terbentuknya kawasan yang berfungsi sebagai taman kota, interaksi sosial, edukasi, dan fungsi ekonomi (Direktorat Jenderal Hortikultura, 2015). Jenis tanaman pada taman hortikultura adalah kombinasi aneka tanaman hortikultura meliputi tanaman sayur-sayuran, tanaman buah-buahan, dan tanaman hias.

Untuk mewujudkan suatu taman hortikultura diperlukan penataan lanskap yang baik. Penataan dapat dilakukan terhadap elemen lanskap sebagai unit pembentuk lanskap, yaitu elemen lunak (soft material) dan elemen keras (hard material). Elemen-elemen tersebut baik secara langsung maupun tidak langsung dapat mempengaruhi penampilan dan kualitas taman itu sendiri. Menurut Arifin et al. (2008), dalam perancangan taman perlu dilakukan pemilihan dan penataan secara detail terhadap elemen-elemen taman agar suatu taman dapat memiliki nilai fungsional dan estetika.

Taman Maccini Sombala merupakan salah satu RTH yang terletak di Kecamatan Maccini, Kota Makassar. Taman ini diharapkan dapat berperan penting dalam perbaikan kualitas lingkungan yang ada di Kota Makassar khususnya di Kecamatan Maccini. Tujuan pembangunan taman ini adalah sebagai taman hortikultura. Pengembangan taman hortikultura ditujukan dengan menerapkan konsep budidaya kebun dengan menanam tanaman yang bermanfaat bagi kehidupan sehari-hari, seperti tanaman obat, tanaman buah, tanaman sayur, dan tanaman bunga yang dapat menambah nilai estetika dari taman.

Jika melihat kondisi Taman Maccini Sombala saat ini, banyak tanaman yang tidak sesuai dengan konsep dan fungsi pembangunan taman tersebut. Begitupun dengan elemen keras yang penempatannya kurang sesuai sehingga fungsinya menjadi kurang maksimal. Penelitian ini dilakukan dengan tujuan untuk mengevaluasi nilai fungsional dan estetika sebagai taman hortikultura dan menyusun rekomendasi berdasarkan hasil evaluasi.

\section{Metode}

Penelitian dilaksanakan di Taman Maccini Sombala yang terletak di Kelurahan Maccini Sombala, Kecamatan Maccini, Kota Makassar, Provinsi Sulawesi Selatan. Penelitian ini berlangsung pada bulan April hingga Juni 2015.

Tahap-tahap dalam kegiatan ini meliputi inventarisasi, analisis, dan sintesis. Inventarisasi dilakukan untuk mengumpulkan data mengenai aspek fisik, biofisik, dan sosial yang dilakukan dengan cara survei, wawancara, dan kuisioner. Analisis yang dilakukan meliputi analisis deskriptif dan kualitatif terhadap data yang dikumpulkan dan penilaian KPI (Key Perfomance Index) berdasarkan modifikasi dari kriteria yang dikemukakan oleh Marcus (1999, 2000), McDowell dan McDowell (1998), dan Stigsdotter dan Grahn (2002) dalam Azi dan Pramukanto (2011). Sintesis dilakukan untuk menyusun rekomendasi sebagai taman hortikultura. 
Penilaian KPI dilakukan terhadap 5 (lima) komponen, yaitu: komponen fisik, komponen kualitas taman, komponen soft material, komponen hard material, dan komponen pengunjung. Nilai KPI ini diperoleh dari hasil perhitungan jumlah nilai aktual dibagi dengan jumlah nilai standar berdasarkan indikator penilaian. Nilai aktual diperoleh dari hasil penilaian yang dilakukan oleh 5 responden ahli di bidang Arsitektur Lanskap yang memberi nilai dari selang nilai 1 sampai 3 , dengan nilai 1 berarti tidak sesuai menurut standar, nilai 2 berarti kurang sesuai dengan standar, dan nilai 3 berarti sesuai dengan standar. Nilai minimum tiap komponen yaitu 1 (satu) dan nilai maksimum tiap komponen yaitu 3 (tiga), sehingga nilai KPI ini memiliki nilai terendah 0.33 dan nilai tertinggi 1 pada setiap indikator dari tiap komponen. Hasil perhitungan nilai KPI digunakan untuk menyusun rekomendasi, yaitu bila hasil nilai $\mathrm{KPI}=1$, maka kondisi taman sudah sesuai kriteria fungsional dan estetika. Namun, bila nilai $\mathrm{KPI}<1$, maka kondisi taman tidak sesuai dengan kriteria yang sudah ditetapkan sehingga perlu diusulkan rekomendasi untuk perbaikan taman.

\section{Hasil dan Pembahasan}

Taman Maccini Sombala (Gambar 1) memiliki luas sekitar 3 ha dan dikelilingi oleh kanal dengan panjang sekitar $1.224 \mathrm{~m}$. Taman dengan topografi datar ini terdiri atas 4 plaza dengan luas yang berbeda, yaitu plaza I memiliki luas sekitar $450 \mathrm{~m}^{2}$ berupa pelataran dengan 4 gazebo, plaza II memiliki luas sekitar $880 \mathrm{~m}^{2}$ berupa pelataran terbuka, plaza III memiliki luas $2.245 \mathrm{~m}^{2}$ berupa pelataran dengan air mancur, dan plaza IV memiliki luas $3.839 \mathrm{~m}^{2}$ berupa pelataran dengan 6 gazebo.

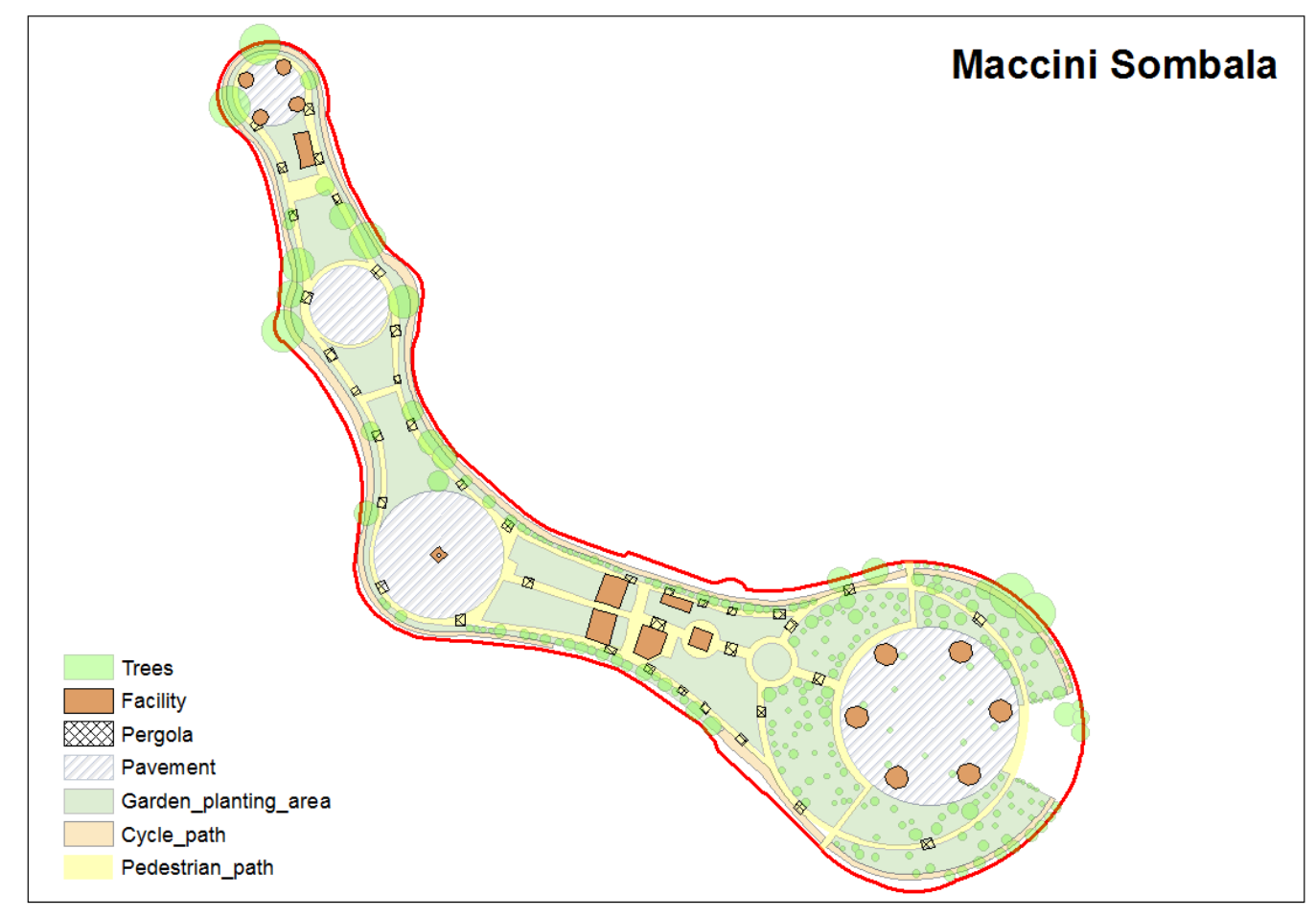

Gambar 1. Kondisi Existing Taman Maccini Sombala 
Taman Maccini Sombala belum memiliki sumber air sehingga air untuk penyiraman tanaman diambil dari luar tapak (Danau Tanjung Bunga). Air kanal di sekitar tapak merupakan air payau yang kurang baik bagi tanaman. Fasilitas yang terdapat di tapak, antara lain, gazebo, pergola, bangku taman, air mancur, toilet, jalur pedestrian, dan jalur sepeda. Beberapa fasilitas yang ada di tapak dapat dilihat pada Gambar 2.
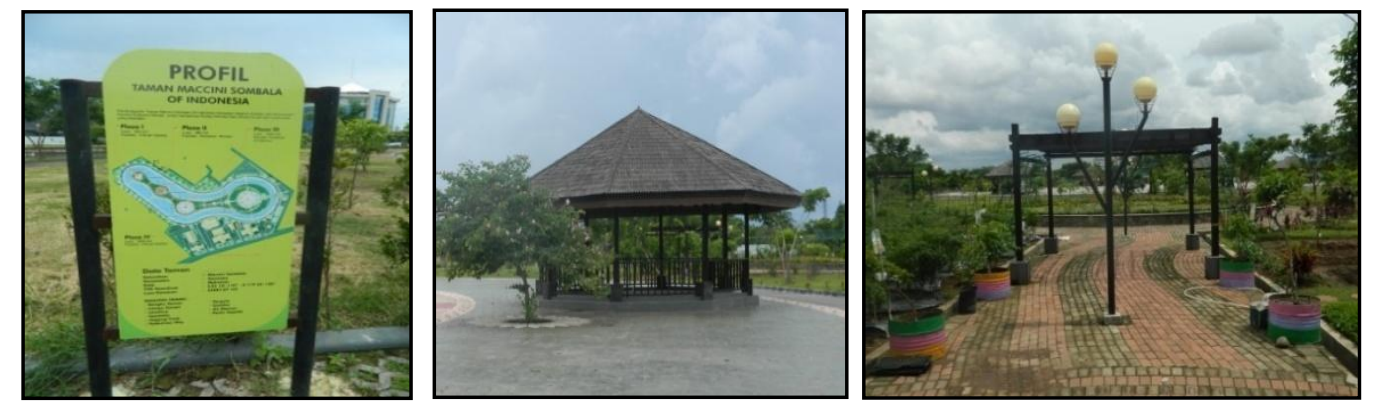

Gambar 2. Fasilitas pada Tapak berupa Papan Informasi, Gazebo, dan Jalur Pedestrian

Jenis tanaman pada tapak beragam mulai dari rumput hingga pohon yang terdiri atas tanaman hias, buah-buahan, dan sayur-sayuran (Gambar 3). Jenis tanaman yang ditanam, antara lain, ki hujan, bintaro, pohon kupu-kupu, angsana, jambu, palem, mangga, jati, srikaya, hanjuang, terong ungu, kacang panjang, puring, tomat, lidah mertua, ubi kayu, cabe, paria, buah naga, dan markisa.
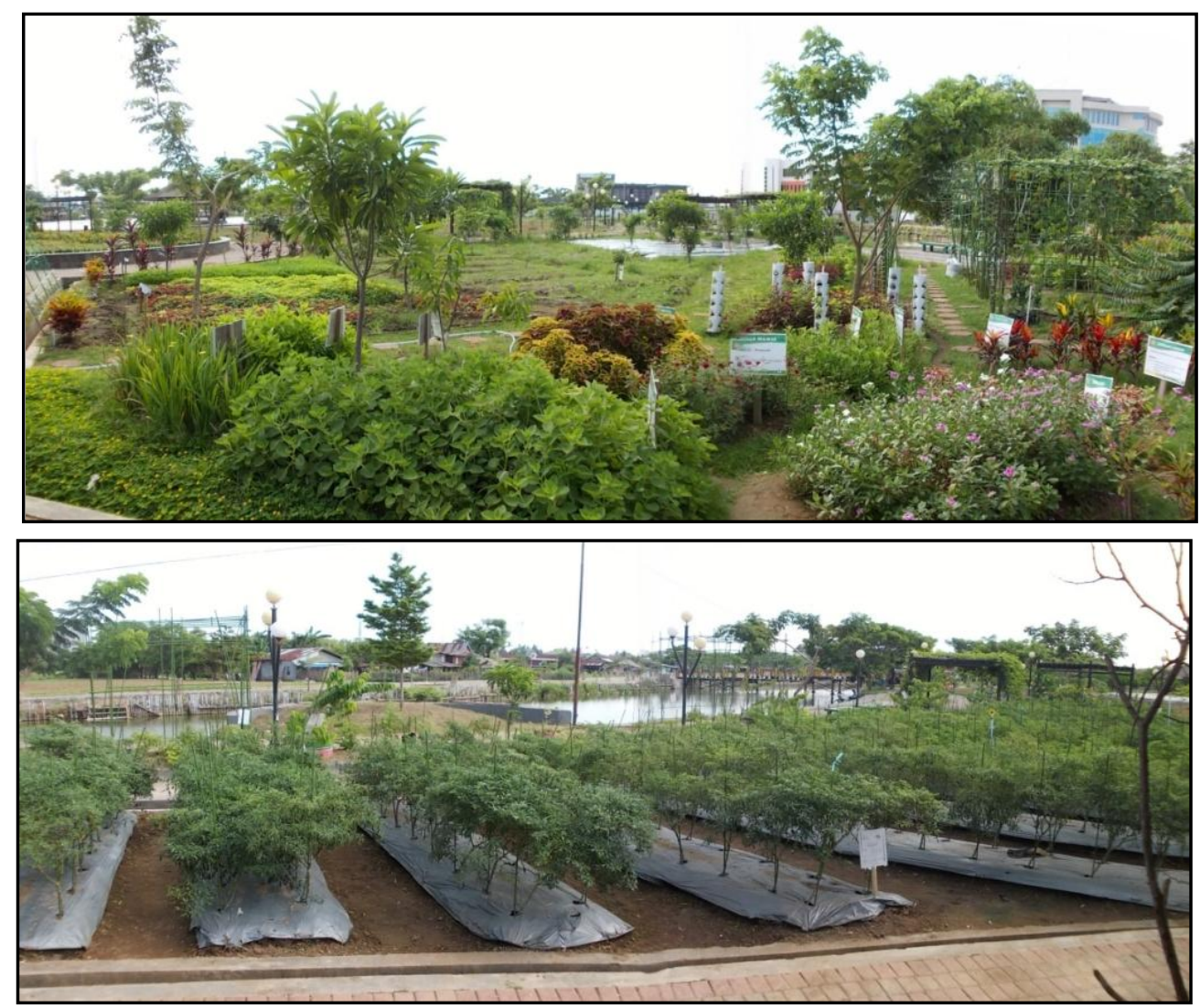

Gambar 3. Elemen tanaman pada tapak 
Taman Maccini Sombala dikelola oleh Dinas Pertanian Tanaman Pangan dan Hortikultura Provinsi Sulawesi Selatan, dengan jumlah pegawai 12 orang dan pekerja kebun 15 orang yang bertanggung jawab untuk memelihara taman. Kegiatan pemeliharaan terutama dilakukan terhadap elemen tanaman, antara lain, pembersihan areal, penyiraman, penyiangan gulma, pemupukan, serta pengendalian hama dan penyakit. terutama elemen tanaman.

Berdasarkan hasil kuisioner yang diberikan kepada 50 responden, diketahui bahwa Taman Maccini Sombala banyak dikunjungi oleh masyarakat terutama pada sore hari (72\%) yang dilakukan pada saat libur akhir pekan (72\%). Aktivitas utama pengunjung adalah bersantai (52\%), dimana pengunjung menghabiskan waktu di taman sekitar 1 jam $(44 \%)$. Pendapat pengunjung mengenai kondisi taman secara umum mengatakan baik $(74 \%)$ dan merasa nyaman berada di taman (92\%). Akan tetapi, sekitar $94 \%$ pengunjung mengatakan bahwa kondisi taman masih perlu perbaikan.

Berdasarkan hasil penilaian responden ahli, nilai KPI yang diperoleh adalah 0.69 dari skala 0 - 1. Nilai KPI dari masing-masing komponen adalah komponen fisik sebesar 0.66 , komponen kualitas taman sebesar 0.67 , komponen soft material sebesar 0.71 , komponen hard material sebesar 0.64 , dan komponen pengunjung sebesar 0.86 (Tabel 1). Total nilai yang diperoleh adalah nilai KPI $<1(\mathrm{KPI}=0.67)$ sehingga dapat disimpulkan bahwa kondisi taman tidak sesuai dengan kriteria yang sudah ditetapkan.

Dari Tabel 1 terlihat bahwa ada 11 poin usulan rekomendasi terkait nilai fungsional dan estetika di Taman Maccini Sombala. Rekomendasi yang diusulkan dibagi menjadi dua, yaitu rekomendasi umum dan rekomendasi khusus. Rekomendasi umum yang diberikan, yaitu: penempatan papan informasi keberadaan taman/sosialisasi (R1), penyediaan jalur jalan yang menarik (R2), penanaman tanaman berbunga dan berwarna dengan visual menarik (R3), penyediaan elemen taman yang aman (R4), penyediaan fungsi keamanan pada elemen taman (R5), penambahan tanaman peneduh (R6), penambahan koleksi tanaman hortikultura dari luar Sulawesi (R7), penyediaan sumber air untuk pemeliharaan tanaman (R8), penyediaan kelengkapan site furniture (R9), penambahan daerah resapan dan perbaikan elemen (R10), serta peningkatan pemeliharaan elemen keras (R11).

Tabel 1. Rekapitulasi Penilaian KPI dan Rekomendasi yang diusulkan

\begin{tabular}{|c|c|c|c|c|c|c|c|c|}
\hline No & Komponen & Indikator & Kualitas Standar & $\begin{array}{l}\text { Nilai } \\
\text { Aktual }\end{array}$ & $\begin{array}{c}\text { Nilai } \\
\text { Standar }\end{array}$ & KPI & $E^{*}$ & $\mathbf{R}^{* *}$ \\
\hline \multirow[t]{5}{*}{1} & Fisik & Aksesibilitas & $\begin{array}{l}\text { Kemudahan lokasi dan akses } \\
\text { pintu masuk }\end{array}$ & 1.6 & 3 & 0.53 & E1 & R1 \\
\hline & & & $\begin{array}{l}\text { Pintu masuk yang } \\
\text { mengundang pengunjung }\end{array}$ & 2.4 & 3 & 0.80 & & \\
\hline & & Sirkulasi & $\begin{array}{l}\text { Kondisi fisik jalur jalan dengan } \\
\text { tekstur dan warna yang } \\
\text { menarik }\end{array}$ & 1.6 & 3 & 0.53 & E2 & $\mathrm{R} 2$ \\
\hline & & & $\begin{array}{l}\text { Lebar jalur jalan sesuai } \\
\text { intensitas dan fungsinya }\end{array}$ & 2.4 & 3 & 0.80 & & \\
\hline & & & Jumlah & 8 & 12 & 0.66 & & \\
\hline \multirow[t]{4}{*}{2} & Kualitas & Pemandangan & Penekanan kesan alami & 2.0 & 3 & 0.66 & & \\
\hline & & $\begin{array}{l}\text { Pencahayaan } \\
\text { dan warna }\end{array}$ & $\begin{array}{l}\text { Tidak gelap, sinar matahari } \\
\text { yang cukup }\end{array}$ & 2.8 & 3 & 0.93 & & \\
\hline & & & $\begin{array}{l}\text { Tidak monoton, perpaduan } \\
\text { warna secara kreatif }\end{array}$ & 1.8 & 3 & 0.60 & E3 & R3 \\
\hline & & Keamanan & Memberikan rasa aman dan & 1.8 & 3 & 0.60 & E4 & $\mathrm{R} 4$ \\
\hline
\end{tabular}




\begin{tabular}{|c|c|c|c|c|c|c|c|c|}
\hline No & Komponen & Indikator & Kualitas Standar & $\begin{array}{l}\text { Nilai } \\
\text { Aktual }\end{array}$ & $\begin{array}{c}\text { Nilai } \\
\text { Standar }\end{array}$ & KPI & $E^{*}$ & $\mathbf{R}^{* *}$ \\
\hline & & & tidak berbahaya pada elemen & & & & & \\
\hline & & & $\begin{array}{l}\text { Bebas dan meminimalisir } \\
\text { gangguan vandalisme }\end{array}$ & 1.6 & 3 & 0.53 & E5 & R5 \\
\hline & & Kenyamanan & $\begin{array}{l}\text { Kenyamanan suhu dan } \\
\text { kenyamanan fisiologis }\end{array}$ & 1.6 & 3 & 0.53 & E6 & $\mathrm{R} 6$ \\
\hline & & & $\begin{array}{l}\text { Desain (site furniture) jelas dan } \\
\text { tidak abstrak }\end{array}$ & 2.6 & 3 & 0.86 & & \\
\hline & & & Jumlah & 14.2 & 21 & 0.67 & & \\
\hline \multirow[t]{7}{*}{3} & $\begin{array}{l}\text { Soft } \\
\text { material }\end{array}$ & Jenis & $\begin{array}{l}\text { Tanaman lokal, tanaman } \\
\text { hortikultura, tanaman hias }\end{array}$ & 2.4 & 3 & 0.80 & & \\
\hline & & Keragaman & $\begin{array}{l}\text { Memiliki keragaman spesies } \\
\text { terutama tanaman hortikultura } \\
\text { yang tinggi }\end{array}$ & 1.8 & 3 & 0.60 & E7 & $\mathrm{R} 7$ \\
\hline & & Bentuk & $\begin{array}{l}\text { Ornamental/dapat dibentuk } \\
\text { dan tidak abstrak }\end{array}$ & 2.0 & 3 & 0.66 & & \\
\hline & & Keamanan & Tidak toksik, tidak berduri & 2.6 & 3 & 0.86 & & \\
\hline & & $\begin{array}{l}\text { Kesesuaian } \\
\text { lokasi/fungsi }\end{array}$ & $\begin{array}{l}\text { Sesuai dengan } \\
\text { lokasi/fungsinya sebagai } \\
\text { taman hortikultura }\end{array}$ & 2.2 & 3 & 0.73 & & \\
\hline & & Pemeliharaan & Mudah dipelihara & 1.8 & 3 & 0.60 & E8 & $\mathrm{R} 8$ \\
\hline & & & Jumlah & 12.8 & 18 & 0.71 & & \\
\hline \multirow[t]{6}{*}{4} & $\begin{array}{l}\text { Hard } \\
\text { material }\end{array}$ & Jenis & $\begin{array}{l}\text { Jalur jalan dan site furniture } \\
\text { (bangku taman, signboard, } \\
\text { tempat sampah, bangunan } \\
\text { peneduh, dll) }\end{array}$ & 1.8 & 3 & 0.60 & E9 & R9 \\
\hline & & Bentuk & $\begin{array}{l}\text { Ornamental/memiliki bentuk } \\
\text { beragam, bertekstur }\end{array}$ & 2.2 & 3 & 0.73 & & \\
\hline & & Keamanan & $\begin{array}{l}\text { Tidak licin dan dilengkapi } \\
\text { aspek keselamatan }\end{array}$ & 1.6 & 3 & 0.53 & E10 & $\mathrm{R} 10$ \\
\hline & & Bahan & $\begin{array}{l}\text { Tidak memantulkan cahaya } \\
\text { panas, tidak mudah pecah }\end{array}$ & 2.4 & 3 & 0.80 & & \\
\hline & & Kondisi & Berfungsi dengan baik & 1.6 & 3 & 0.53 & E11 & R11 \\
\hline & & & Jumlah & 9.6 & 15 & 0.64 & & \\
\hline \multirow[t]{5}{*}{5} & Pengunjung & Pengunjung & Semua golongan umur & 2.8 & 3 & 0.93 & & \\
\hline & & Jenis aktivitas & $\begin{array}{l}\text { Mendukung aktivitas aktif dan } \\
\text { pasif }\end{array}$ & 2.6 & 3 & 0.86 & & \\
\hline & & & $\begin{array}{l}\text { Aktivitas sesuai dengan fungsi } \\
\text { ruang dan elemen }\end{array}$ & 2.4 & 3 & 0.80 & & \\
\hline & & & Jumlah & 7.8 & 9 & 0.86 & & \\
\hline & & & Nilai KPI & 52.4 & 75 & 0.69 & & \\
\hline
\end{tabular}

Keterangan:

KPI $=\frac{\text { Nilai aktual (bobot 1-3) }}{\text { Nilai standar (bobot 3) }}$

Nilai $0-0.33=$ tidak sesuai dengan standar; $0.34-0.67=$ kurang sesuai dengan standar; $0.68-1.00=$ sesuai dengan standar

${ }^{*}$ E adalah kode evaluasi (E) ke-n

${ }^{* *} \mathrm{R}$ adalah kode rekomendasi $(\mathrm{R})$ ke-n

Rekomendasi yang diusulkan juga disesuaikan dengan hasil konfirmasi pengunjung taman sebagai berikut :

a. Perlunya papan informasi di beberapa jalan poros mengenai keberadaan Taman Maccini Sombala agar menarik perhatian pengunjung karena taman ini mempunyai lokasi yang sedikit tersembunyi. 
b. Perlunya perawatan pada jalur sirkulasi yang sudah rusak dan pemotongan rumput yang tumbuh liar serta penataan jalur sirkulasi dengan warna yang cerah agar lebih menarik.

c. Perlunya penanaman tanaman yang memiliki visual yang menarik baik dari daun, bunga, maupun batang sehingga taman tidak berkesan monoton.

d. Perlunya penambahan papan informasi dan papan himbauan kepada pengunjung taman agar fasilitas taman dapat digunakan dengan baik.

e. Perlunya pemagaran pada sisi kanal untuk menghindari terjadinya kecelakaan.

f. Perlunya penambahan tanaman peneduh di sekitar area terbuka agar dapat menurunkan suhu di sekitar tapak.

g. Perlunya petugas keamanan untuk menjaga keamanan dan kenyamanan di dalam taman.

h. Perlunya penambahan koleksi tanaman dari beberapa daerah di Indonesia sebagai bahan referensi tanaman hortikultura serta pemilihan tanaman yang menarik dan dapat dikonsumsi langsung.

i. Perlunya penataan pola penanaman agar taman terkesan rapi.

j. Perlunya penggantian tanaman yang sudah layu atau mati.

k. Perlunya penambahan dan perbaikan beberapa fasilitas dan utilitas taman.

I. Perlu dipertimbangkan biaya retribusi bagi pengunjung yang dapat dimanfaatkan untuk biaya pemeliharaan taman.

m. Pentingnya menumbuhkan rasa tanggung jawab pengunjung untuk menjaga kebersihan taman.

n. Perlu adanya wisata petik buah langsung.

o. Perlu adanya wisata air untuk menambah daya tarik taman.

Rekomendasi khusus sebagai taman hortikultura yaitu pengembangan taman untuk kebun percobaan, penangkaran benih, taman pendidikan dan penelitian, serta sebagai taman wisata hortikultura. Taman Maccini Sombala diharapkan dapat menjadi lokasi percontohan dalam pengelolaan kebun hortikultura bagi masyarakat. Selain itu, dapat menjadi tempat perbanyakan dan konservasi varietas-varietas hortikultura yang unik, unggul, dan memiliki nilai komersial. Sebagai taman hortikultura, Taman Maccini Sombala juga dapat menjadi taman pendidikan dan penelitian bagi masyarakat untuk mempelajari mengenai budidaya tanaman hortikultura, selain sebagai taman wisata hortikultura.

\section{Simpulan}

Simpulan yang didapatkan dari penelitian ini adalah sebagai berikut :

1. Nilai Key Perfomance Index (KPI) dari seluruh komponen sebesar 0.69 dari skala 0 -1 yang berarti bahwa kondisi Taman Maccini Sombala tidak sesuai dengan kriteria yang telah ditetapkan.

2. Untuk meningkatkan nilai fungsional dan estetika Taman Maccini Sombala sebagai taman hortikultura diusulkan rekomendasi yang dibagi menjadi rekomendasi umum dan rekomendasi khusus. Rekomendasi umum yang diberikan yaitu penambahan dan perbaikan soft material dan hard material, sedangkan rekomendasi khusus sebagai 
taman hortikultura yaitu pengembangan taman untuk kebun percobaan, penangkaran benih, taman pendidikan dan penelitian, serta sebagai taman wisata hortikultura.

\section{Daftar Pustaka}

Arifin, H.S., Munandar, A. Arifin, N.H.S., Pramukanto, Q., Damayanti, V.D. 2008. Buku Panduan Penataan Taman Umum, Penanaman Tanaman, Penanganan Sampah dan Pemberdayaan Masyarakat. Sampoerna Hijau Kotaku Hijau, Bogor.

Azi, M.A.H., Pramukanto, Q. 2011. Studi Evaluasi Taman Kota sebagai Taman Terapeutik (Studi Kasus: Taman Cilaki Atas, Kota Bandung). Jurnal Lanskap Indonesia, 3(2): 80-85.

Direktorat Jenderal Hortikultura. 2015. Hortipark (Taman Hortikultura). Available online at: http://hortikultura.pertanian.go.id/?p=343 (accessed 5 October 2015). 